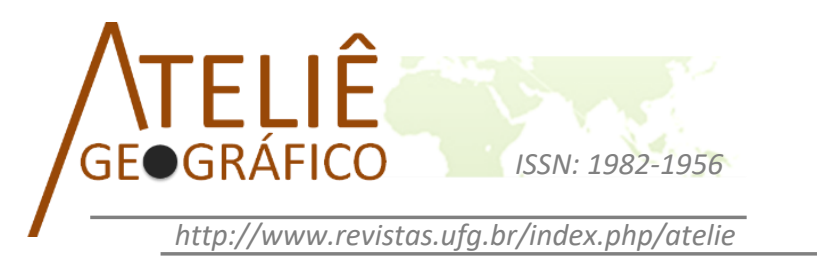

\title{
Processos de recontextualização nas Aulas de Geografia
}

\author{
Recontextualization processes in Geography Classes
}

\section{Procesos de recontextualización en las Clases de Geografía}

\author{
Claudia do Carmo Rosa \\ Universidade Estadual de Goiás \\ claudiamorosa@yahoo.com.br \\ Vanilton Camilo de Souza \\ Universidade Federal de Goiás \\ souzavanilton@gmail.com
}

\begin{abstract}
Resumo
Este artigo tem como enfoque central discutir os fundamentos didático-pedagógicos da Geografia Escolar que se recontextualizam no conjunto da prática pedagógica por meio dos conteúdos geográficos. Nesse intento, tecer-se-á considerações basilares acerca da teoria de Basil Bernstein, com destaque para o conceito de recontextualização, tendo por base o modelo do discurso pedagógico. Na sequência, apresentaremos uma discussão sobre o papel dos temas e conteúdos do ensino de Geografia utilizando situações da prática pedagógica no processo de construção de discursos pedagógicos na Geografia Escolar. No contexto da prática docente do professor de Geografia, será evidenciado o conteúdo "Migração", com o objetivo de compreender os processos recontextualizadores nas aulas de Geografia do Ensino Fundamental, anos finais. Os dados empíricos a serem apresentados são parte da pesquisa de tese intitulada Professores Iniciantes de Geografia: Processos de Recontextualização da Formação Inicial no Contexto da Prática Docente. Os resultados apontaram para processos de recontextualização que evidenciam potencialidades docentes relativas à Didática da Geografia e as fragilidades relativas aos conteúdos geográficos.

Palavras-Chave: Teoria de Bernstein. Ensino de Geografia. Recontextualização.
\end{abstract}

\begin{abstract}
This essay has as its main focus the discussion about didactic and pedagogic foundations of school geography that are recontextualized in pedagogical practice through geographical concepts. In this intent, basilar considerations upon Basin Bernstein theory are made with highlight to recontextualization's concept, based on pedagogical discourse model. Subsequently, it follows a discussion about the role of themes and concepts in geography's teaching using situations of pedagogical practice
\end{abstract}

Ateliê Geográfico - Goiânia-GO, v. 13, n. 3, dez/2018, p. 117 - 135 
in the process of pedagogical discourse construction at school geography. In an educational context of geography teacher, 'Migration' concept is evidenced with the goal of comprehending recontextualizing processes at geography classes on the later years of primary school. Empirical data presented is part of a thesis research titled 'Initial geography teachers: recontextualizing processes on early formation at educational practice contexts'. The results points out to recontextualizing processes that evidences teaching potentialities regarding geographic didactic and fragilities concerning geographical concepts.

Keywords: Bernstein's Theory; Geography's teaching; Recontextualization.

\begin{abstract}
Resumen
Este artículo tiene como enfoque central discutir los fundamentos didácticopedagógicos de la Geografía Escolar que se recontextualizan en el conjunto de la práctica pedagógica por medio de los contenidos geográficos. En ese intento, se tejen consideraciones basilares acerca de la teoría de Basil Bernstein, con destaque para el concepto de recontextualización, teniendo como base el modelo del discurso pedagógico. Posteriormente, presentaremos una discusión sobre el papel de los temas y contenidos de la enseñanza de Geografía utilizando situaciones de la práctica pedagógica en el proceso de construcción de discursos pedagógicos en la Geografía Escolar. En el contexto de la práctica docente del profesor de Geografía, se evidenciará el contenido "Migración", con el objetivo de comprender los procesos recontextualizadores en las clases de Geografía de la Enseñanza Fundamental, años finales. Los datos empíricos a ser presentados son parte de la investigación de tesis titulada Profesores Iniciantes de Geografía: Procesos de Recontextualización de la Formación Inicial en el Contexto de la Práctica Docente. Los resultados apuntaron a procesos de recontextualización que evidencian potencialidades docentes relativas a la Didáctica de la Geografía y las fragilidades relativas a los contenidos geográficos.
\end{abstract}

Palabras clave: Teoría de Bernstein. Enseñanza de Geografía. Recontextualización.

\title{
Introdução
}

Partimos do pressuposto de que a materialização da prática pedagógica se dá pela integração dos conhecimentos e ações que, numa análise conjuntural, proporciona o agir num diálogo com a própria ação e o enfrentamento dos desafios encontrados em diferentes circunstâncias nas aulas de Geografia. É preciso, para tanto, considerar o fazer pedagógico baseado em fundamentos teórico-metodológicos que subsidiam a organização do trabalho do professor, o qual considera-se um sujeito e, como tal, pode produzir alternativas próprias, posicionar-se diante das prescrições e dos modelos de ensino e aprendizagem, e também recusá-los. Sendo assim, a prática pedagógica demanda, à luz da teoria, o desenvolvimento da formação profissional, por considerar que toda prática é, também teoria, e que ambas se apoiam nela.

Nesse viés, considera-se necessário questionar quais fundamentos teóricometodológicos os professores de Geografia utilizam em sua atuação nas escolas de Educação Básica. Como se dão, na prática pedagógica do professor de Geografia, os processos de recontextualização ao se trabalhar os conteúdos geográficos? Estes 
questionamentos nos direcionam a outra pergunta: "Em que medida os conhecimentos teórico-metodológicos da Ciência Geográfica são recontextualizados na construção da Geografia Escolar pelos professores no contexto da sala de aula?".

$\mathrm{Na}$ intencionalidade de discutir essas referidas questões, o presente texto apresenta uma breve consideração a respeito da teoria de Basil Bernstein, com destaque para o conceito de recontextualização, tendo por base o modelo do discurso pedagógico. $\mathrm{Na}$ sequência, expõe uma discussão sobre o papel dos temas e conteúdos do ensino de Geografia utilizando-se de situações da prática pedagógica no processo de construção de uma Geografia Escolar, considerando em que medida o conteúdo geográfico indica dimensões no processo de recontextualização. Foi destacado, na sequência, o conteúdo "Migração", trabalhado por uma professora de Geografia da rede municipal de Goiânia, onde conseguimos identificar as dimensões da teoria e do contexto na sua prática de ensino.

Vale ressaltar que os dados empíricos a serem apresentados neste artigo, são parte da pesquisa de tese intitulada Professores Iniciantes de Geografia: Processos de Recontextualização da Formação Inicial no Contexto da Prática Docente (ROSA, 2017). Na referida tese, o objetivo geral foi compreender como ocorre a prática pedagógica dos professores iniciantes de Geografia, tendo por referência sua formação inicial e os processos de recontextualização na sala de aula. Assim, desenvolveu-se uma pesquisa diretamente centrada na formação e atuação docente realizada com professores iniciantes de Geografia da Região Metropolitana de Goiânia e de Anápolis.

Os sujeitos participantes da pesquisa foram docentes habilitados em Geografia que estavam exercendo a profissão de professor desta disciplina, na Educação Básica, com mínimo de um ano e máximo de sete anos de docência. E para a análise dos dados validar o significado que os sujeitos deram ao objeto de estudo, os instrumentos de coleta de informações utilizados foram o questionário on-line, a entrevista aberta e a observação de aulas. Suscintamente, um total de 33 professores de Geografia responderam ao questionário on-line. Desse quantitativo, nove professores participaram da entrevista e, dentre estes, dois foram selecionados para a observação de aulas de Geografia, vinculados a contextos distintos e realidades específicas. Neste texto, o enfoque central foi a observação das aulas da professora Beatriz (nome fictício), atentando-se para os processos de recontextualização dos conteúdos geográficos, no contexto da sala de aula. A escolha das informações oriundas das práticas dessa docente decorre do fato de que a mesma, conseguiu durante a observação, trabalhar com o conteúdo de Geografia, como será salientado a posteriori nesse trabalho.

\section{A teoria de Basil Bernstein e o conceito de recontextualização}

Basil Bernstein nasceu em Londres no ano de 1924, filho de uma família de imigrantes judeus, e morreu em 2000, tendo iniciado sua carreira acadêmica na Universidade de Londres, na década de 1960. Ocupou a cátedra Karl Mannheim, foi chefe 
do Departamento de Sociologia da Educação e, quando se aposentou, recebeu o título de professor emérito.

Bernstein foi um grande sociólogo e suas publicações tiveram início em 1958, e desenvolveram-se continuamente até o ano 2000. A evolução das suas ideias aparece fundamentalmente em cinco volumes (Class, codes and control), nas quais o autor elabora a teoria dos códigos sociais e educativos, e suas implicações para a reprodução social. Juntamente com Michael Young, Basil Bernstein passou a ser referido no campo da pesquisa educacional brasileira como um dos principais teóricos da Nova Sociologia da Educação.

Sua teoria tem sido amplamente utilizada por áreas de conhecimento tão diversas que chegou ao campo educacional e agora, mais especificamente, na Geografia. Vale ressaltar que foram identificadas duas teses defendidas nesse campo do conhecimento (SOARES, 2011; STEFENON, 2017) e as reflexões desse sobre o teórico na formação do professor de Geografia (ASCENSÃO; VALADÃO, (2017). A teoria de Bernstein expressa em suas obras é marcante, aspecto este enfatizado por diferentes pesquisadores que escrevem sobre o autor (LEITE, 2004; MAINARDES; STREMEL, 2010; MORAIS, 2004; MORAIS; NEVES, 2007; SANTOS, 2003). Sua obra é complexa, densa, dialética e com um nível de teorização que exige do leitor um referencial de outras interpretações no campo da Linguagem, Educação, Filosofia, Sociologia, etc., para a compreensão de suas ideias, pois o mesmo aponta diferentes elementos constituintes para se pensar em diferentes contextos e possibilidades e, diante isso, tomar posicionamento.

Basil Bernstein fundamenta-se em uma constelação de conceitos e/ou categorias de análise que dão suporte à sua teorização. Esses conceitos são palavras-chave dos modelos teóricos de Bernstein, dentre os quais, se destacam: classificação, enquadramento, poder, controle, código, dispositivo pedagógico, regras distributivas, regras recontextualizadoras, regras de avaliação, discurso pedagógico, recontextualização, discurso vertical, discurso horizontal, dentre outros. Considera-se que esses conceitos são retomados em suas diferentes obras, já que "Bernstein é um autor fiel a si mesmo, cuja obra consiste em um refinamento cada vez maior e mais elaborado, do ponto de vista teórico, de conceitos com alto nível de abstração que vão se tornando cada vez mais complexos" (SANTOS, 2003, p. 17).

Os conceitos teóricos de Bernstein devem ser considerados dentro de um macro e de um micro contexto, tornando-se a sua preocupação principal operacionalizá-los de forma a permitir que os mesmos se traduzam tanto nas relações externas quanto nas internas, formas pelas quais as relações de poder e os princípios de controle acabam por ser reproduzidos dentro da realidade escolar.

Mesmo considerando a riqueza e a complexidade da teoria de Bernstein, no que se refere aos dois principais modelos que sintetizam as ideias fundamentais contidas em sua teoria Modelo de Reprodução e Transformação Cultural e Modelo do Discurso Pedagógico, neste texto, constata-se o modelo do discurso pedagógico com enfoque para o conceito de recontextualização. Isso por considerar que a prática do professor na sala de 
aula é, na sua essência, práticas recontextualizadas em que se evidenciam dimensões do conhecimento específico de um campo disciplinar em um dado contexto escolar. Essas são dimensões importantes para a compreensão do que se denomina Geografia Escolar.

De acordo com Bernstein (1998), o discurso é uma categoria abstrata, resultado de uma construção, de uma produção. $O$ discurso não pode ser reduzido a uma simples realização de linguagem, cada processo discursivo pode ser considerado como produto de uma rede complexa de relações sociais e, por sua vez, cada discurso é um mecanismo de poder. O discurso pedagógico não é um repertório de discursos, mas pode ser definido pela relação que incorpora o discurso instrucional (DI) no discurso regulador (DR). O primeiro é um discurso de competência e o segundo é um discurso de ordem, ou seja, um discurso que cria ordem, relação e identidade especializadas. Essa relação DI/DR mostra que, subjacente à forma como os conhecimentos são transmitidos na relação pedagógica (DI), estão os princípios e normas de conduta social (DR).

O discurso regulador (DR), nesse sentido, é a pré-condição para qualquer discurso pedagógico, pois a regulação moral das relações sociais de transmissão/aquisição é anterior à transmissão de competências e, é também uma condição para essa transmissão. Para tanto, Bernstein utiliza esse conceito como princípio de inserção de um discurso instrucional (DI), de habilidades específicas, em um discurso regulador, ou regulativo (DR), de ordem moral, que possui dominação sobre o primeiro. Desse modo, o discurso pedagógico é o resultado da combinação desses dois discursos.

O modelo do discurso pedagógico de Bernstein $(1990,2000)$ é centrado em um conjunto complexo de relações, pressupondo a intervenção de diferentes campos e contextos que conduzem à produção e reprodução do discurso pedagógico ao longo do aparelho pedagógico. De acordo com esse modelo, a gramática interna do discurso pedagógico é fornecida pelo aparelho pedagógico, através das regras de distribuição, de recontextualização e de avaliação, hierarquicamente relacionadas.

Bernstein (1998), explicita como as regras estão organizadas e inter-relacionadas:

Para começar, direi que o dispositivo pedagógico fornece a gramática intrínseca do discurso pedagógico (isto é, a gramática, no sentido metafórico). Considerarei, em seguida, a gramática intrínseca do discurso pedagógico que o dispositivo fornece, principalmente através de três conjuntos de regras relacionadas entre si: regras distributivas, regras de recontextualização e regras de avaliação. Essas regras mantêm um relacionamento particular entre si. Ou seja, estão relacionadas de forma hierárquica, no sentido de que as regras de recontextualização são derivadas das distributivas, e as avaliadoras são derivadas das recontextualizantes. Existe uma inter-relação necessária entre essas regras e também há relações de poder entre elas (BERNSTEIN, 1998, p. 58, tradução nossa).

As regras de distribuição ocorrem no campo de produção do discurso pedagógico marcadas por regras especializadas de controle e poder, que partilham aquilo que pode ser 
transmitido, quem é que pode transmitir, como será transmitido e a quem transmitir. Essas regras difundem as formas de conhecimento e de consciência a diferentes grupos e classes sociais, regulam quem tem acesso a qual conhecimento transmitido e por quem e em que condições, o pensável (o conhecimento acessível, reproduzido) e o impensável (o conhecimento que ainda não foi produzido), estabelecendo os limites da recontextualização do discurso pedagógico, porque regulam as regras de recontextualização. Pode-se dizer que as regras de distribuição estão sendo cada vez mais controladas pelo Estado, por ser este, o principal mantenedor das agências e/ou programas de financiamentos de pesquisas. Estes, por sua vez, regulam o que deve ser transmitido e como deve ser transmitido.

As regras recontextualizadoras referem-se ao contexto recontextualizador, estruturado por campos diversos, cujo conjunto é denominado pelo autor de "campo recontextualizador" (BERNSTEIN, 1996, p. 91). Neste campo, atuam, de acordo com as regras distributivas, os agentes recontextualizadores, que modificam um texto selecionado, que sofre uma transformação antes de sua relocação (num determinado campo, num determinado contexto) no discurso pedagógico.

Por isso, é imprescindível considerar nas regras recontextualizadoras as diversas agências educacionais do Estado, o que inclui as pesquisas produzidas e a fiscalização, feitas por essas agências, as universidades com suas pesquisas e produções teóricas, as publicações em livros e revistas, assim como o campo educacional e as práticas pedagógicas dos professores que, juntos, validam as influências sobre as transformações de um texto.

As regras avaliativas estabelecem os critérios para a prática pedagógica, definindo os níveis que se devem alcançar, "as regras de avaliação atuam seletivamente sobre os conteúdos, a forma de transmissão e sua distribuição para os diferentes grupos de alunos em diferentes contextos" (BERNSTEIN, 1998, p. 144, tradução nossa). As regras de avaliação regulam a relação entre a transmissão e a aquisição dos discursos pedagógicos específicos e, assim, determinam diretamente a prática pedagógica.

O modelo do discurso pedagógico inclui três níveis fundamentais de análise: a geração, a recontextualização e a transmissão. Os dois primeiros níveis de análise (geração e recontextualização) estão relacionados com a produção, e o terceiro nível (transmissão) está ligado à reprodução do discurso pedagógico. $\mathrm{O}$ modelo evidencia que o discurso pedagógico é determinado por um conjunto complexo de relações que pressupõem a intervenção de diferentes campos e contextos. É possível, também, analisar as relações que se estabelecem entre os vários níveis desde o macro nível, do campo de Estado, até ao micro nível, da sala de aula.

O nível III, Transmissão, ao ser inserido nos contextos de reprodução pedagógica (diferentes níveis de ensino), pode estar sujeito a princípios de recontextualização, dependendo do domínio específico de uma dada escola e, sobretudo, da prática pedagógica do professor, que, por sua vez, é mediada por diferentes fatores, entre eles, seus princípios de formação profissional. Assim, o discurso pedagógico reproduzido na escola depende 
das diferentes relações que caracterizam os contextos específicos de ensino-aprendizagem, das práticas pedagógicas dos professores, que podem, efetivamente, influenciar essas relações e, desse modo, representar fatores de recontextualização do discurso educativo.

A questão central consiste em compreender como o conhecimento científico, produzido no campo do controle simbólico, é recontextualizado em Geografia Escolar por meio da prática pedagógica dos professores iniciantes na constituição do conhecimento geográfico escolar.

Assim sendo, pressupõe-se que a teoria de Bernstein contribui na descrição e na análise de como esse conhecimento científico, advindo da formação inicial dos professores de Geografia, se apresenta no contexto da Geografia Escolar por meio dos processos de recontextualização da prática pedagógica. Para tanto, é preciso considerar, também, outros elementos, agentes e agências (programas, currículos, livros didáticos) reguladores do processo ensino-aprendizagem.

Num sentido trivial do termo, recontextualização implica tirar algo de um contexto e colocar em outro. Assim, a regra da recontextualização pressupõe um momento anterior, de contextualização. De acordo com Leite (2007), a recontextualização aparece com maior frequência nas reflexões sobre a composição do conhecimento escolar, e o modelo teórico desenvolvido por Bernstein, se propõe analisar as relações pedagógicas e desvelar a complexidade das práticas escolares articuladas com os contextos sociais, daí sua complexidade.

Pretende-se neste artigo, pensar a Geografia ensinada nas escolas de Educação Básica, mas antes de tudo, pensar nesta Geografia como um discurso recontextualizado. Ela é resultado de princípios recontextualizadores que deslocam a produção do discurso desenvolvido pelos pesquisadores na universidade ou em instituições equivalentes, no contexto primário e, se relocam e se refocalizam no contexto secundário da reprodução do discurso.

A reprodução desse discurso pode, também, ser afetada pelas relações de poder do campo recontextualizador entre a escola e o campo de contextualização primária dos adquirentes (alunos) - família/comunidade - a fim de tornar seu próprio discurso regulativo mais eficaz ou, inversamente, pode exercer sua própria influência sobre o campo recontextualizador da escola, afetando a prática dos transmissores (professores).

Por mais complexo que seja, isso significa dizer que a produção e reprodução do discurso pedagógico resulta de discursos recontextualizados que mostram as diversas relações, os variados agentes e elementos que compõem o processo inicial de um discurso, e o efeito subsequente do discurso num contexto local (comunidade/escola/sala de aula/ professores/alunos).

Mesmo considerando a relativa independência entre essa Geografia acadêmica e a que é ensinada na escola, a Geografia Escolar parte de uma seleção da ampla totalidade da Geografia acadêmica produzida no contexto primário, operando, entretanto com outra 
lógica, que impõe outros objetivos, conteúdos, métodos e ritmos no processo de ensinoaprendizagem. Isso se deve ao seguinte fato:

As regras de recontextualização regulam não apenas a seleção, a sequência, o compassamento e as relações com outros sujeitos, mas também a teoria de instrução da qual as regras de transmissão são derivadas. [...]. Dessa forma, a ordem, a relação e a identidade na transmissão do discurso instrucional estão, elas próprias, embutidas nos princípios de ordem, relação e identidade do discurso regulativo. O discurso pedagógico é, pois, um princípio/discurso recontextualizador que embute a competência na ordem e a ordem na competência ou, mais, geralmente, o cognitivo no moral e o moral no cognitivo (BERNSTEIN, 1996, p. 261).

Tendo por base as discussões referidas, vale ressaltar que a prática pedagógica dos professores de Geografia, submetida às mais diversas influências pode levar a um enriquecimento ou a um empobrecimento do discurso pedagógico de reprodução. Por isso, é importante que os professores estejam conscientes de que as potencialidades e limites da sua mediação pedagógica dependem também das recontextualizações que podem ocorrer aos vários níveis do sistema educacional, e que sua formação profissional é um dos elementos basilares no exercício da docência.

Essa preocupação também é suscitada por Morais e Neves (2007), quando há a advertência de que os professores precisam ter elevado nível de conhecimento e capacidades científicas, pois não existem metodologias tão excelentes que possam compensar uma proficiência científica pobre. Os professores então, devem reconhecer que a formação profissional é basilar para a atuação docente, seja no contexto da graduação ou da pós-graduação.

Ao fato de que os professores precisam ter elevado nível de conhecimento e capacidades científicas, as autoras denominam o nível de exigência conceitual. Esse conceito, inicialmente usado por Morais, refere-se à complexidade do processo de ensinoaprendizagem em termos de capacidades científicas. Acredita-se que um elevado nível de exigência conceitual é crucial para que a prática pedagógica dos professores não se limite a uma prática tradicional e simples.

O estudo realizado por Pires, Morais e Neves (2004), salienta:

Elevar o nível de exigência conceptual constitui um passo crucial para que todas [as crianças] tenham acesso a um elevado nível de literacia científica e, consequentemente, tenham acesso ao texto científico mais valorizado, quer pela comunidade científica, quer pela sociedade em geral (PIRES; MORAIS; NEVES, 2004, p. 127).

Mas não há dúvidas de que os professores de Geografia precisam refletir sobre suas práticas, preocupar-se com sua própria construção pessoal e profissional, e investigar a melhor forma de adapta-las ao contexto escolar, a partir dos processos de 
recontextualização dos conteúdos geográficos. Nesse sentido, apresentamos a seguir, uma discussão sobre o lugar que o conteúdo geográfico pode assumir nos processos de recontextualização, considerando os elementos constitutivos como fundamentos teóricometodológicos no processo de ensino-aprendizagem de Geografia.

\section{Conteúdos geográficos: códigos discursivos da Geografia Escolar}

Para adentrar na discussão sobre conteúdos geográficos, se faz necessário questionar: Qual é o conteúdo de Geografia que se instrui nos diversos níveis de ensino? Há diferença entre tema/fenômeno/assunto e o que se denomina conteúdo? Se sim, qual seria essa distinção? Qual relação ou distinção se estabelece (ou se pode estabelecer) entre eles? Que dimensão do conteúdo geográfico é constitutivo do discurso pedagógico?

É comum nos currículos oficiais, nos projetos pedagógicos da escola, nos planos de ensino, que os conteúdos geográficos sejam identificados com um rol de termos que geralmente podem expressar relações com a Ciência: climatologia, relevo, agricultura, meio ambiente, população, biomas, etc. Nem sempre esta é uma boa expressão para se dizer que tais palavras apontam aspectos de conteúdo geográfico. Termos, a rigor, podem ser tomados para o ensino de qualquer outra disciplina na escola, dependendo da abordagem da disciplina de referência. Um interessante exercício rumo à Geografia é constituí-lo em temas próximos à disciplina. Para tanto, é pertinente relacionar essas palavras a uma determinada porção do espaço. Esse exercício de ir transformando um tema em um conteúdo disciplinar, agrega elementos para a construção de um discurso pedagógico da Geografia Escolar. Conforme o tema "população", que associado a uma dimensão espacial, se apresenta com dimensões geográficas, mesmo que ainda de forma genérica, como: população brasileira, população da América Latina, população do meu município, movimentos populacionais no mundo, dentre outros. Para Azambuja (2018, p. 29), "o tema indica parte ou recorte da realidade a ser abstraída, pensada e analisada como objeto de estudo". O tema diz respeito a um recorte genérico que pode ser abordado sob a perspectiva de qualquer área do conhecimento. $\mathrm{O}$ tema não expressa, necessariamente, um conteúdo da Geografia, pois, para torná-lo um conteúdo é necessário agregar mais elementos próprios da disciplina, o que será abordado a seguir.

Comumente, denomina-se conteúdo geográfico um conjunto de informações sobre uma dada temática que sintetiza dimensões do conhecimento da Geografia, que explicita um conjunto de princípios sobre como o conhecimento geográfico é sistematizado e ensinado, além de valores sociais e culturais, constituídos ao longo do tempo e que podem, no âmbito do ensino, se constituir em conteúdos procedimentais e atitudinais. Essa definição, no entanto, é genérica e nem sempre consegue se concretizar ao fazer geográfico na escola, desde o planejamento, ao momento de elencar o tema a ser trabalhado e os conteúdos a serem ensinados, até a sua abordagem na sala de aula. O que é o geográfico em um conteúdo de Geografia? Como tomamos um tema como referência para o ensino e o constituímos em conteúdo de Geografia? 
Um tema pode ser uma importante referência para ensinar a Geografia pelo fato de que muitos deles têm diversos elementos do campo, o que permite maior ou menor exercício em torná-lo geográfico. Ao depreender especificamente a ele sem o exercício de agregar referenciais da área do conhecimento, corre-se o risco de ensinar conteúdos que nem sempre versam sobre a disciplina de base desse conhecimento. E por que isso ocorre? Avançar geograficamente a partir de um tema é estabelecer algumas conexões com o método geográfico, é tomar como referência alguns dos conceitos estruturantes da Geografia, é usar as referências teórico-metodológicas da Geografia Escolar ao seu ensino na sala de aula, é se atualizar com as pesquisas na área acessando novos conhecimentos e agregando-os ao seu ensino.

Tomar como referência o exercício de reunir a um dado tema às referências da Geografia e constituí-lo conteúdo geográfico pode ser exemplificado a partir do esquema da Figura 1.

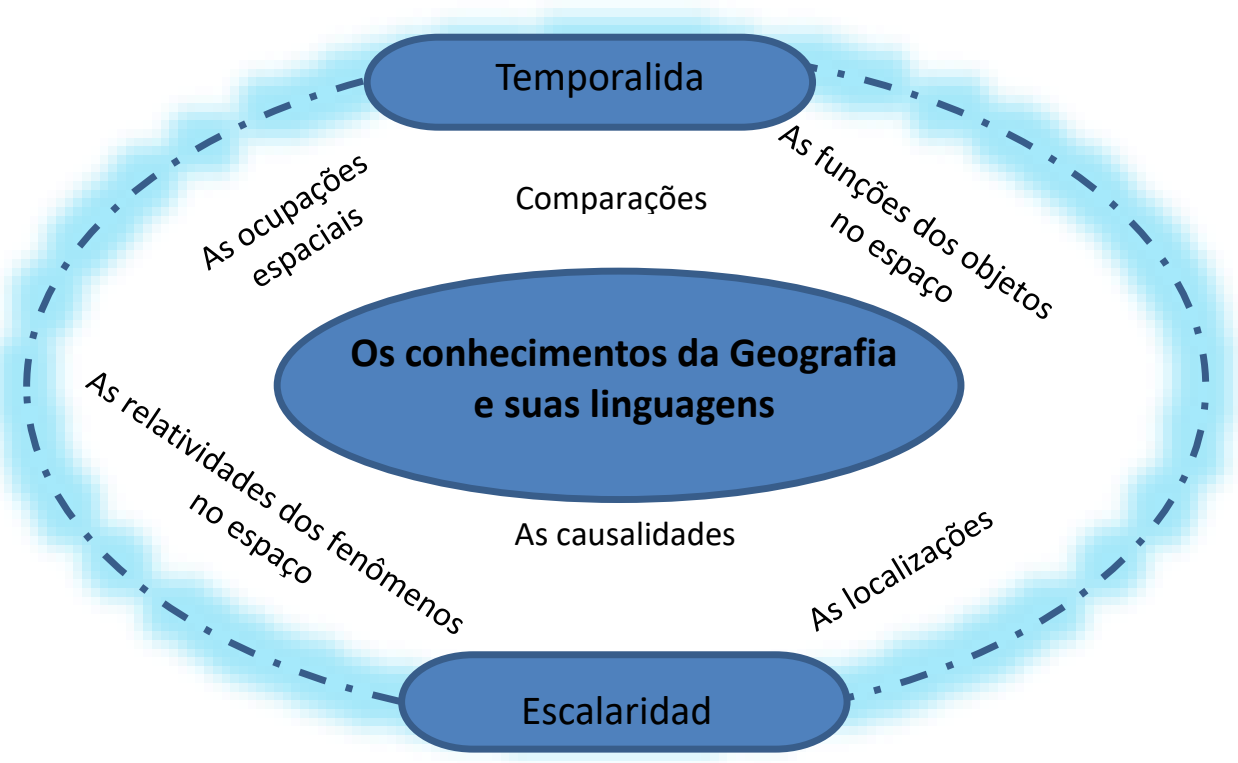

Figura 01: Elementos constitutivos dos conteúdos de Geografia

Um conteúdo é geográfico quando nele se percebe alguns aspectos do conhecimento da disciplina (categorias, conceitos e os métodos) e as suas linguagens. Nele, é fundamental considerar as dimensões de temporalidade do tema num dado espaço, em direção a constituí-lo em fenômeno geográfico, como ele se comporta ao longo do tempo e como se estabelece as conexões e comportamentos entre o passado e o presente. Além da temporalidade, a escalaridade é outra dimensão fundante na constituição de um conteúdo geográfico. 
A dimensão escalar de um conteúdo é um importante sentido no caminho da compreensão de como um mesmo fenômeno se relaciona com outros espaços mais longínquos: regional, nacional e mundial. Nesse exercício de pensar a escala do tema, é significativa a associação com as respectivas temporalidades. Essas duas dimensões de exercitar um conteúdo geográfico se diferenciam de acordo com os métodos de referência da ciência. É dizer que a temporalidade e a escalaridade de um fenômeno no espaço, sob as bases da dialética, se diferenciam da escalaridade e temporalidade de base positivista, por exemplo. Portanto, serão conteúdos geográficos completamente distintos.

A partir dessas considerações, uma constituição mais operacional de se concretizar um conteúdo geográfico, é se prender aos aspectos relativos à localidade, causalidade, funcionalidade e relatividade dos fenômenos espaciais. Essas dimensões são também constitutivas do discurso pedagógico da Geografia Escolar e são, do mesmo modo, dimensões muito importantes ao processo de recontextualização da dimensão disciplinar para a dimensão escolar.

A localização dos fenômenos no espaço é um curioso ponto de partida do pensamento geográfico. Pensar essa dimensão é responder às clássicas perguntas dessa concepção, por exemplo, onde se localizam. É constituir, segundo Santos (1997), a composição das formas espaciais. Para além da localização, é importante pensar a causa desses fenômenos no espaço, remetendo-os às perguntas: Por que estão nesse lugar e não em outro lugar? Quem o construiu? Como? Outro importante exercício na constituição de um conteúdo geográfico é se aproximar às funções que cada objeto constituinte desse espaço exerce numa dada sociedade, numa dada localidade com seus sujeitos. Pensar a funcionalidade dos objetos é outra dimensão constitutiva do pensamento geográfico e pode potencializar a dimensão social do conteúdo. A dinamicidade das funções dos objetos no espaço geográfico decorre, ainda, em considera-las ao longo do tempo, pois, as funções alteram-se a cada momento, considerando a dinâmica da sociedade. Ampliando a compreensão de como compreender os fenômenos espaciais, é essencial considerar a relatividade dos olhares sobre o fenômeno, por ponderar que as perspectivas teóricas, epistemológicas, sociais e culturais orientam um determinado posicionamento do fenômeno no espaço e, por sua vez, no pensamento geográfico.

O discurso pedagógico de um conteúdo de Geografia é constituído, a partir do exposto, das dimensões oriundas do conhecimento próprio da Geografia, pelas linguagens utilizadas nas representações desse conhecimento, pelas conexões e abordagens efetivadas pelo professor na sala de aula, pelos contextos que estão inseridos na escola, e pelas relações que se estabelecem entre os sujeitos constitutivos do espaço escolar.

Nessa perspectiva, com base na observação das aulas da professora Beatriz (nome fictício) tornou-se possível observar os processos de recontextualização dos conteúdos geográficos no contexto da sala de aula, com destaque para o conteúdo "as migrações da população na constituição do território brasileiro". Ao ater-se sobre os fenômenos populacionais na Geografia, temática abordada na pesquisa de Rosa (2017), e que constitui parte desse texto, não será, a princípio, qualquer informação sobre esse tema que o 
constituirá conteúdo de Geografia. Sabe-se, no entanto, que muitos conceitos referentes ao tema população possuem forte apelo espacial e geográfico: migração, distribuição e densidade populacional, por exemplo.

Há de se pensar o fenômeno na sua relação teórico-metodológica com a Ciência Geográfica, os tipos de linguagens apropriadas para ensinar o conteúdo (textos, gráficos, mapas, tabelas, pinturas, fotografias, filmes, etc.), as dimensões históricas do mesmo, as interseções entre diversos lugares do planeta, as formas pelas quais o fenômeno se apresenta nos diferentes locais da superfície terrestre, a causalidade e a funcionalidade do mesmo no espaço, e os diferentes olhares existentes sobre os fenômenos populacionais.

\section{Recontextualizando os conteúdos geográficos}

Com referência à teoria de Bernstein, a escola requer a viabilização de demandas institucionais para atender a comunidade, professores, alunos e outros agentes. Para tanto, a escola também é regida pelo campo do Estado e precisa cumprir regras estabelecidas, que, por sua vez, recebem influências de diferentes outros campos recontextualizadores até chegar ao conjunto da sala de aula. Porém, o campo de contextualização primária pode interferir na escola e, quiçá, no campo de recontextualização oficial, assim como o professor.

Sob tal enfoque, ao referir-se ao professor nessas relações contraditórias, é presumível considerar que os profissionais envolvidos na educação geográfica requerem pensar sobre o que os alunos devem aprender na escola e como ensinar os conteúdos geográficos a eles. Aqui, pondera-se que o papel da Geografia Escolar é articular os conteúdos com a Ciência Geográfica, com a concepção de que o professor é sujeito mediador e detém a autonomia de interpretar, modificar e ressignificar os conteúdos que serão abordados com os alunos em sala de aula.

Considera-se que os conteúdos de ensino possam permitir a compreensão e o enfrentamento das exigências teóricas e práticas da vida social. Melhor dizendo, os conteúdos, como são organizados em matérias de ensino, podem expressar os resultados da atividade prática dos homens nas suas múltiplas relações com o mundo em que vivem. Por isso, é válido ponderar os elementos que compõem os conteúdos escolares: os agentes definidores, as fontes de seleção, suas perspectivas e abordagens, pois todos esses aspectos são dimensões que interferem direta ou indiretamente no trabalho do professor.

$\mathrm{O}$ aspecto central a ser destacado neste trabalho, refere-se aos processos de recontextualização a partir da prática pedagógica da professora de Geografia, aqui denominada ficticiamente de Beatriz. A mencionada professora concluiu o curso de Licenciatura em Geografia no ano de 2009, na Universidade Federal de Goiás (UFG). É professora efetiva, leciona aulas de Geografia na rede municipal de ensino de Goiânia, e trabalha com cinco turmas referentes ao Ciclo III. Foram observadas 20 aulas durante os meses de maio, junho e agosto do ano de 2016. É imprescindível salientar que a prática da 
professora está conectada ao contexto histórico, social, econômico e cultural, o que resulta ações constituídas de valores, influências, conhecimentos, convicções, ideias, ideais e subjetividades que expressam a maneira como a professora (re)constrói sua relação com a docência e reage no decorrer da carreira profissional.

As Diretrizes Curriculares na rede de ensino de Goiânia, apontam os objetivos que o professor deve trabalhar durante todo o ciclo, e o próprio professor seleciona os conteúdos de acordo com os objetivos e a realidade do contexto escolar. Segundo a professora, o currículo permite ao docente, a possibilidade de controle na gestão e organização do processo de ensino-aprendizagem, o que aumenta sua responsabilidade no relativo às aprendizagens dos alunos.

No decorrer das aulas, observou-se, no entanto, que a professora Beatriz segue o livro didático. Nesse sentido, o currículo oficial não é elemento preponderante na prática pedagógica da professora Beatriz e, sim, pode ser visto como uma orientação que regula os princípios de "o quê" ensinar e a professora possui uma certa autonomia para reestruturar as prescrições curriculares nas suas classes. Se ela tem autonomia diante do currículo da Rede de Ensino do Município, ela, em boa medida, sucumbe aos conteúdos do livro. Na sua prática pedagógica cotidiana, a professora Beatriz toma o livro didático como o principal recurso das atividades realizadas em sala. Ela salienta que o livro é a fonte de conhecimentos que todos os alunos têm em mãos, por isso, realiza leituras dos capítulos com os alunos e direciona a eles, as atividades. Beatriz relata que "o livro é bom, mas sempre falta", por essa razão, ela complementa com outras questões no caderno e, sempre que possível, utiliza outros recursos e fontes para ensinar Geografia. Isso demonstra princípios da formação profissional que reverberam em recontextualizações advindas da utilização do livro didático. Na realidade, tal percurso pressupõe afirmar que o poder de recontextualização dos professores é frágil. Daí eles se apegam a outras recontextualizações, entre elas, o livro didático.

A docente, de alguma forma, seleciona os exercícios do livro, ou seja, ela não utiliza todas as atividades contidas no livro didático e as respostas também não estão de acordo com o manual adotado. Ela apresenta uma dinamicidade que consiste em explicar novamente o conteúdo abordado, atem-se às respostas dos alunos e sintetiza uma resposta no quadro. Os alunos que não fizeram a tarefa são obrigados a fazê-la, copiando as perguntas do livro, concomitantemente com as respostas do quadro.

Segundo Berstein (1996), há uma relação de classificação e enquadramento forte nesse momento. Segundo o autor, esses conceitos constituem uma dimensão importante no discurso pedagógico e nos processos de recontextualização. O termo classificação (poder) é usado para descrever as relações de poder e controle do que é ensinado e aprendido. Já o termo enquadramento (controle) é usado para descrever as relações de poder e controle que influenciam como o processo de ensino-aprendizagem é conduzido.

De acordo com o autor, a classificação refere-se à natureza da diferenciação entre conteúdos e áreas do conhecimento. Onde a classificação é forte, os conteúdos estão separados por limites sólidos. A classificação, por sua vez, é fraca onde há uma reduzida 
separação entre conteúdos e áreas de conhecimento. O termo enquadramento refere-se ao grau de controle do que é transmitido, do que é recebido e do que pode ou não pode ser transmitido na relação pedagógica. Um enquadramento forte indica que o transmissor (nesse caso a professora Beatriz) regula explicitamente o conteúdo, o sequenciamento, a forma, o compassamento e o discurso de como constituirá o processo de aprendizagem. Já o enquadramento será fraco se o transmissor tem um controle menor sobre os elementos da prática pedagógica, situação a ser relatada posteriormente. A professora Beatriz relata: "De alguma forma, os alunos estão fazendo e registrando no caderno o que deve ser estudado". Finalizada a correção das atividades, ela verifica se os alunos que não haviam feito o exercício, conseguiram terminar para, em seguida, conceder o visto, valendo a metade da pontuação.

Se não há tarefas de casa a serem corrigidas e avaliadas, a professora Beatriz inicia sua aula sempre fazendo uma recapitulação da aula anterior para dar continuidade ao conteúdo abordado. Se for conteúdo novo, ela escreve no quadro-giz, o tema a ser estudado e começa um diálogo com os alunos, problematizando o tema em consonância com a realidade imediata, promovendo, assim, envolvimento e participação dos alunos (enquadramento fraco). Ela explica o conteúdo, possibilitando intervenções dos alunos e, sempre que possível, utiliza exemplos do cotidiano. Ela diz que é uma forma de dar significado àquilo que está sendo ensinado relacionando-o com a vida dos alunos.

Usualmente, durante a explicação do conteúdo, a professora Beatriz realiza a leitura do texto do livro didático. Ela pede em ordem aleatória a cada aluno para fazer a leitura de dois ou três parágrafos. À medida que explica o conteúdo, a professora sintetiza com frases e/ou palavras-chave no quadro-giz. Durante a realização das aulas, alguns alunos conversam e se dispersam, mas a professora Beatriz sempre tenta envolvê-los na aula, fazendo questionamentos sobre o conteúdo trabalhado.

Considera-se que o conteúdo é um dos componentes mais importantes do processo ensino-aprendizagem em Geografia e também uma questão central, que não envolve meramente o ato de ensinar determinados conteúdos, mas, sim, de ensinar uma forma de pensar o conteúdo. Selecionar o quê ensinar e como ensinar é um dos maiores desafios para os professores, em consonância com a necessidade de decidir sobre como investir na qualidade de ensino de Geografia ou na quantidade de conteúdos a serem abordados. Nesse processo de ensinar a pensar o conteúdo, considera-se a classificação e o enquadramento fracos, como dimensões importantes nos processos de recontextualização e na estruturação do discurso pedagógico do professor de Geografia.

Selecionar é uma intervenção de poder (teoria bernsteiniana) assim como privilegiar determinados conteúdos em detrimento de outros. No dia a dia, acredita-se que, nos processos de recontextualização da prática pedagógica, o professor iniciante de Geografia se apoia em aspectos objetivos (currículo oficial, livro didático, Projeto Político Pedagógico, planos de ensino, diretrizes curriculares, metodologia, recursos didáticos) e subjetivos (formação inicial e continuada, valores, relações interpessoais, experiência profissional). Contudo, independentemente da extensão que a recontextualização possa 
assumir, o sentido que o professor imprime à sua prática pedagógica depende, entre esses vários aspectos, dele próprio. Por parte do professor, deve haver um elevado nível de conhecimento da Geografia, condição essencial para que os alunos possam ter uma visão de disciplina que tenha sentido para a vida e não uma Geografia reduzida à aprendizagem de fatos.

Em relação aos fenômenos populacionais, a professora Beatriz começa suas atividades laborais realizando a chamada de frequência dos alunos e em seguida, inicia o estudo sobre migrações. Ela começa perguntando aos alunos: "Quem nasceu em Goiânia? Quem nasceu fora de Goiânia?”. As respostas são variadas: na classe, há alunos de Goiânia e de outras cidades goianas e até mesmo, alunos do Maranhão. Seguidamente, pergunta: "Onde seus pais nasceram?". Outras respostas aparecem, salientando as diferentes cidades e estados brasileiros.

Após essa problematização, a professora retoma o conceito de migração, e diz que as pessoas sempre migraram e que isso implica uma historicidade que vai desde o homem nômade até ao sedentarismo dos dias atuais. Mesmo tendo residência fixa, o homem ainda migra.

A professora Beatriz novamente pergunta: "Por que seus pais migraram?”. É nítida a intenção da professora de estabelecer uma relação que associe o estudado com a realidade do aluno, a partir de questões problematizadoras que lhe permitam pensar, refletir, elaborar respostas, participar da aula e promover o significado do conteúdo estudado.

Quando aborda os tipos de migração, a professora busca relacionar o conteúdo com a experiência de pessoas da própria escola. Em certo momento, faz referência a uma professora que mora em Senador Canedo e trabalha em Goiânia. Também expõe o exemplo de uma aluna da escola que nasceu no Japão e mora em Goiânia, e a experiência da própria professora Beatriz, que morava em Caldas Novas e, por conta dos estudos e, depois, do trabalho, mudou-se para Goiânia. A aula se estabelece na modalidade explicativa e dialogada. O diálogo entre a professora e os alunos é aproximado por meio dos exemplos que possibilitam observar um enquadramento fraco numa relação mais simétrica entre esses sujeitos, permitindo o envolvimento ativo dos alunos no processo ensino-aprendizagem.

Com base nesses destaques, a aula da Professora Beatriz confere com o posicionamento de Aguiar (2016), quando este apresenta a seguinte propositura:

Iniciar a aula com uma pergunta pode ser um ponto de partida para ensinar os conteúdos geográficos aos discentes. O que eles conhecem sobre determinado assunto revela-se ser fundamental para o professor poder ajudá-los a entender o que vivenciam no seu dia a dia e a estabelecer relações entre a experiência do vivido e os conhecimentos curriculares da Geografia (AGUIAR, 2016, p. 14). 
$\mathrm{Na}$ aula relatada torna-se visível a interlocução. A professora Beatriz ao utilizar questionamentos baseados nos exemplos da vida das pessoas, emprega uma forma de ilustrar e promover o entendimento sobre o conteúdo. Ela fez o seguinte comentário: " $A s$ aulas de uma professora na UFG foram fundamentais para mim. No primeiro ano de graduação a professora disse, e ela jamais esqueceu: Se quer que o aluno da Educação Básica aprenda, utilize exemplos. É uma maneira de concretizar e visualizar o que está sendo abordado/estudado".

Esse fato é muito frequente nas aulas da professora. Todas as vezes que Beatriz inicia a aula retomando a explicação da aula anterior, ela questiona os alunos para que estes participem da aula e por fim, menciona os exemplos dados por eles. É uma forma de relembrar o que foi abordado e de prender a atenção dos alunos a partir dos exemplos da prática cotidiana. No entanto, a migração é um conteúdo que poderia ser trabalhado com o uso de diferentes linguagens, o que a professora não fez. Não houve processo de sistematização em que fossem abordados mais elementos geográficos na discussão do fenômeno espacial "migração", tais como: as causalidades do fenômeno, os tipos de manifestações do espaço, as relações de escalaridade geográfica do fenômeno, dentre outros. Vários podem ser os motivos dessa dificuldade da professora, no seu processo de recontextualização, trazer para a sala de aula, conhecimentos da Geografia mais presente na sua prática. Pode estar relacionada à falta de tempo para o cumprimento do planejamento escolar. Nesse dia, a professora Beatriz explicou dois capítulos do livro, pois o conteúdo abordado encontrava-se na prova e ela teria apenas duas aulas mais para realizar as atividades, fazer a correção e a revisão dos conteúdos. Como também, pode estar relacionada há uma fragilidade em torno do seu conhecimento em Geografia, entre outros.

As aulas dialogadas, por sua vez, foram os momentos em que no discurso pedagógico da professora, imprimiu-se aulas mais interessantes no processo de construção de um conhecimento mais autônomo por parte dos alunos, além de ter sido os momentos em que a assimetria da relação de poder entre o aluno e o professor esteve menor e o sentido da Geografia com o cotidiano dos alunos tiveram maior significado para os discentes.

\section{Considerações finais}

A referência à teoria de Bernstein na área de ensino-aprendizagem de Geografia exprime possibilidade de discussão das relações pedagógicas inseridas na prática pedagógica dos professores iniciantes de Geografia em termos de discurso pedagógico dimensão comunicativa dessas relações - e dos processos da recontextualização transformações de acordo com os contextos e influências. A teoria bernsteiniana conduz a investigação do cotidiano escolar e da sala de aula, potencializando, assim, o processo de produção do conhecimento escolar e sua distinção das outras formas de conhecimento, a 
partir da compreensão do discurso pedagógico do professor, advindo dos campos de produção e reprodução do discurso.

O professor é um sujeito relevante no processo de ensino-aprendizagem do aluno, pois é ele, no contexto da sala de aula, "quem faz a mediação entre o aluno e o conhecimento sistematizado da Geografia". Por conseguinte, faz-se necessário levar em consideração inúmeros fatores, agentes e relações que influenciam e viabilizam a efetivação das aulas de Geografia com atenção aos microcontexto e o macrocontexto em que se inserem as práticas observadas.

Por meio da teoria, identificamos que o discurso pedagógico do professor de Geografia, no seu processo de recontextualização possui, por um lado, aspectos importantes desse discurso quando se remetem à dimensão da Didática da Geografia como dimensão primária da recontextualização. Ficou evidente que a professora Beatriz considera os aspectos do cotidiano como referência importante para abordar o conteúdo "migração". Por outro lado, o conteúdo do livro didático estabelece o eixo estruturador do discurso, revelando fragilidades da autonomia da professora, relativas, ou à gestão do planejamento ou ao conhecimento geográfico.

A teoria de Bernstein permitiu compreender como os textos educacionais são organizados e como são construídos, postos em circulação, contextualizados, apreendidos e também como estes sofrem mudanças, ou seja, são recontextualizados. Assim, nos processos de recontextualização, os textos (por exemplo, currículo), desde o campo de produção do conhecimento, sofrem inúmeras transformações até que estejam prontos para o uso dos professores e dos alunos na sala de aula. Por essa razão, entre o que está escrito no currículo e o que verdadeiramente ocorre na sala de aula, há certamente diferentes recontextualizações.

\section{Referências}

AGUIAR, W. G. de. Didática da Geografia: Construindo Aulas. Curitiba: CRV, 2016. ASCENSÃO, V. R.; VALADÃO, R. C. Complexidade conceitual na construção do conhecimento do conteúdo por professores de Geografia. Revista Brasileira de Educação Geográfica, v. 7, n. 14, 2017, p. 05-23.

AZAMBUJA, L. D. de. A Geografia do Brasil na Educação Básica. Curitiba: CRV, 2018.

BERNSTEIN, B. Pedagogía, Control Simbólico e Identidad: Teoria, Investigación y Crítica. Madrid: Ediciones Morata, 1998.

BERNSTEIN, B. A Estruturação do Discurso Pedagógico: Classe, Códigos e Controle. Petrópolis: Vozes, 1996. 
BERNSTEIN, B. Class, Codes and Control: The Structuring of Pedagogic Discourse. v. IV, London: Routledge, 1990.

BERNSTEIN, B. A Pedagogização do Conhecimento: Estudos sobre Recontextualização. Cadernos de Pesquisa, n. 120, p. 75-110, novembro, 2000.

LEITE, M. S. Recontextualização e Transposição Didática: Introdução à Leitura de Basil Bernstein e Yves Chevallard. Araraquara, SP: Junqueira \& Marin, 2007.

MAINARDES, J.; STREMEL, S. A Teoria de Basil Bernstein e algumas de suas Contribuições para as Pesquisas sobre Políticas Educacionais e Curriculares. Revista Teias, v. 11, n. 22, p. 1-24, maio/agosto, 2010.

MORAIS, A. M.; NEVES, I. P. A Teoria de Basil Bernstein: Alguns Aspectos Fundamentais. Revista Práxis Educativa, v. 2, n. 2, p. 115-130, 2007. Disponível em: http://www.revistas2.uepg.br/index.php/praxiseducativa/article/view/313/321. Acesso em: 17/09/2018

MORAIS, A. M. Basil Bernstein: Sociologia para a Educação. In: TEODORO, A.; TORRES, C. Educação Crítica e Utopia: Perspectivas para o Século XXI, p. 73-88. Lisboa: Edições Afrontamento, 2004.

PIRES, D.; MORAIS, A. M.; NEVES, I. P. Desenvolvimento Científico nos Primeiros Anos de Escolaridade: Estudo de Características Sociológicas Específicas da Prática Pedagógica. Revista de Educação, v. XII, n.2, p. 119-132, 2004.

ROSA, C. C. Professores iniciantes de Geografia: Processo de Recontextualizações da Formação Inicial no Contexto da Prática Pedagógica. 2017. 208 f. Tese (Doutorado em Geografia) - Universidade Federal de Goiás, Goiânia, 2017.

SANTOS, L. L. C. P. Bernstein e o Campo Educacional: Relevância, Influências e Incompreensões. Cadernos de Pesquisa, n. 120, p. 15-49, novembro, 2003.

SANTOS, Milton. Espaço e Método. São Paulo: Nobel, 1997.

SOARES, M. O. O Novo Paradigma Produtivo e os Parâmetros Curriculares Nacionais de Geografia. 2011. 185 f. Tese (Doutorado em Geografia Humana) - Universidade de São Paulo, São Paulo, 2011.

STEFENON, D. L. Desigualdades Educacionais e Esvaziamento Curricular: um Estudo a partir do Caso da Recontextualização dos Saberes Geográficos na Escola. 2017. 216 f. Tese (Doutorado em Educação) - Faculdade de Educação da Universidade de São Paulo, São Paulo, 2017. 


\section{Claudia do Carmo Rosa}

Professora de Estágio Supervisionado e de Didática da Geografia da Universidade Estadual de Goiás - UEG. Possui doutorado em Geografia pela Universidade Federal de Goiás.

Rua 7, n. 27, Vila 31 de Março. CEP: 15400-000, Inhumas - GO

E-mail: claudiamorosa@yahoo.com.br

\section{Vanilton Camilo de Souza}

Professor de Estágio Supervisionado e de Didática da Geografia da Universidade Federal de Goiás - UFG. Possui doutorado em Geografia pela Universidade Federal de Goiás

Rua 6, q. 8, 1. 10B, Chácaras Califórnia. CEP: 74690-807, Goiânia-GO

E-mail: souzavanilton@gmail.com

Recebido para publicação em março de 2018 Aprovado para publicação em julho de 2018 